\title{
MEDIA PROMOSI DAN INFORMASI PADA PT. GARDENA KARYA ANUGRAH BERBENTUK VIDEO COMPANY PROFILE
}

\author{
Mukti Budiarto ${ }^{1}$ \\ Ulis Bella ${ }^{2}$ \\ Nita yuliania ${ }^{3}$ \\ Dosen AMIK Raharja Informatika ${ }^{1,2}$, STIMK Raharja Jurusan Teknik Informatika ${ }^{3}$ \\ Jl. Jendral Sudirman No. 40, Modern Cikokol, Tangerang \\ Email : $\underline{\text { mukti@raharja.info }}{ }^{1)}$, ulis.bella@raharja.info $^{2)}$, nita.yuliani@ raharja.info $^{3)}$
}

\begin{abstract}
ABSTRAK
Saat ini keterbukaan akses informasi memungkinkan informasi dapat dengan mudah diperoleh kapanpun dan dimanapun. Informasi menjadi hal penting, karena dengan informasi orang akan mendapat semua yang diinginkan. Penyebaran informasi tersebar melalui media cetak atupun media elektronik berbentuk multimedia, dari media itulah masyarakat dapat memperoleh informasi. PT. Gardena Karya Anugrah adalah salah satu perusahaan produk furniture yang terletak Jl. Adi Sucipto No.128 Kelurahan Pajang, Kecamatan Benda Kota Tangerang, PT. Gardena Karya Anugrah yang terbilang belum cukup lama di bentuk, PT. Gardena Karya Anugrah yang terbilang baru dan masih menggunakan media lisan, tulisan, majalah dan website, maka pihak PT. Gardena Karya Anugrah Membutuhkan Media Company Profile untuk menunjang promosi PT. Gardena Karya Anugrah Untuk menginformasikan kepada masyarakat Umum khususnya untuk calon customer agar tertarik untuk memesan berbagai furniture PT. Gardena Karya Anugrah. Pada konsep tersebut terdapat tahapan preproduction, production dan postproduction. Agar menghasilkan rancangan media berbasis video company profile komunikasi dan informasi yang baik dan berkualitas digunakan aplikasi penunjang Adobe Photoshop CS6, Adobe Premier CS6 dan Adobe Corel Video Studio X5.

Kata Kunci : media, video,komunikasi, informasi dan promosi.
\end{abstract}

\begin{abstract}
Currently open access to information allows information to be easily obtained anytime and anywhere. Information is important, because with information people will get everything they want. Dissemination of information spread through print media atupun electronic media in the form of multimedia, from media that community can get information. PT. Gardena Karya Anugrah is one furniture product company located at Jl. Adi Sucipto No.128 Kelurahan Pajang, Tangerang City District Object, PT. Gardena Karya Anugrah which is not quite long enough in the form, PT. Gardena Karya Anugrah which is fairly new and still use oral media, writings, magazines and website, then the PT. Gardena Karya Anugrah Requires Media Company Profile to support the promotion of PT. Gardena Karya Anugrah To inform the general public especially for prospective customers interested in ordering various furniture PT. Gardena Karya Anugrah. In the concept there are preproduction, production and postproduction stages. In order to produce video-based media design company profile communication and good information and quality applications used Adobe Photoshop CS6 support, Adobe Premier CS6 and Adobe Corel Video Studio X5.

Keywords: media, video, communication, information and promotion.
\end{abstract}




\section{PENDAHULUAN}

Berbagai jenis teknologi telah banyak diciptakan oleh manusia untuk mempermudah manusia dalam melakukan pekerjaannya. Sebagai salah satu teknologi yang berkembang ialah teknologi di bidang multimedia. multimedia diperlukan dalam hal-hal tertentu. Contohnya, pada suatu promosi dan informasi yang membutuhkan video company promosi yang dikarenakan akan menambah pendapatan perusahaan. PT. Gardena Karya Anugrah Kota Tangerang, maka pihak perusahaan mengembangkan lagi beberapa jenis produk furniture dengan model diantaranya Dewata Etnic Design yang mempunyai acuan produk pada kerajinan-kerajinan asli Indonesia seperti furniture yang berbahan dasar dari rotan dan eceng gondok dan yang mengandung unsur ukiran khas dari Jepara Jawa Tengah. Kemudian Natural Home and Décor yang mempunyai acuan produk pada model simplesity dan unsur modern yang memakai unsur besi. Selain itu terdapat produk berlabel Victory Collection, produk ini menganut gaya klasik yang menggunakan ornamen-ornamen romawi kuno.

\section{RUMUSAN MASALAH}

Berdasarkan hasil wawancara pada PT. Gardena Karya Anugrah Kota Tangerang, promosi pada saat ini masih menggunakan manual. Manual di sini diartikan masih mulut kemulut atau melalui desain promosi yang ada di PT. Gardena Karya Anugrah Kota Tangerang. Dapat diambil satu masalah yang mempengaruhi promosi tersebut tersebut diantaranya pendapatan atau pembeli dari customer akan berkurang, sehingga akan pendapatan yang menurun. Sehingga diperlukannya media video berbentuk video profile PT. Gardena Karya Anugrah Kota Tangerang, sehingga masyarakat lebih mengetahui.

\section{LANDASAN TEORI}

\section{Pengertian Perancangan}

penggambaran, perencanaan dan pembuatan sketsa atau pengaturan dari beberapa elemen yang terpisah ke dalam satu kesatuan yang utuh dan berfungsi.

\section{Konsep Dasar Media}

Media adalah tempat dimana kita bisa menyebarkan informasi kepada masyarakat luas tentang apa yang kita ketahui biasanya media terdiri dari teks, gambar atau foto maupun audio jika diperlukan. (Karunia Suci Lestari)

\section{Konsep Dasar Video \\ Pengertian Video}

teknologi untuk menangkap, merekam, memproses, mentransmisikan dan menata ulang gambar bergerak. Biasanya menggunakan film seluloid, sinyal elektronik, atau media digital. Video juga bisa dikatakan sebagai gabungan gambar-gambar mati yang dibaca berurutan dalam suatu waktu dengan kecepatan tertentu. Gambar-gambar yang digabung tersebut dinamakan frame dan kecepatan pembacaan gambar disebut dengan frame rate, dengan satufps.

\section{Konsep Dasar Video Profile}

aporan yang memberikan gambaran tentang sejarah, status saat ini, dan tujuan masa depan sebuah bisnis. Sebuah profil perusahaan bisnis dapat sesingkat satu halaman, atau 
mengandung data yang cukup untuk mengisi beberapa halaman. Walaupun ada sejumlah format yang berbeda yang digunakan menyusun sebuah profil, ada beberapa jenis informasi penting yang wajib disertakan.

\section{Konsep Dasar Promosi}

suatu kegiatan dalam pemasaran di suatu perusahaan atau pada usaha yang berupaya untuk mempertahankan kelangsungan dalam hidup perusahaan/usaha. Promosi bisa berupa komunikasi dari suatu perusaan/usaha suatu produk/jasa agar terkenal dimasyarakat luas.

\section{Bentuk Promosi}

\section{Advertising (Iklan)}

bentuk promosi non personal dengan menggunakan berbagai media yang ditujukan untuk merangsang pembelian. Menurut Kotler (2002:658), periklanan didefinisikan sebagai bentuk penyajian dan promosi ide, barang atau jasa secara nonpersonal oleh suatu sponsor tertentu yang memerlukan pembayaran.

\section{Personal Selling (Penjualan Personal)}

Dikatakan bahwa Personal penjualan Personal merupakan alat paling efektif pada tahap tertentu dalam proses keputusan pembelian, teruatam dalam menentukan pembelian, keyakinan dan tindakan yang akan diputuskan.

\section{Sales Promotion (Promosi Penjualan)}

uatu bentuk promosi diluar ketiga bentuk diatas yang ditujukan untuk merangsang pembelian. Sales Promotion (promosi penjualan) merupakan suatu tindakan persuasif secara langsung yang menawarkan insentif atau nilai lebih untuk suatu produk pada sales force, distributor atau konsumen dengan tujuan utama untuk menciptakan penjualan yang segera. Pada intinya kegiatan promosi bermanfaat, untuk membujuk calon pembeli agar membeli produk atau jasa yang kita tawarkan. Promosi penjualan menggambarkan insentif-insentif dan hadiah-hadiah untuk membuat para pelanggan membeli barang-barang perusahaan seacara langsung. Maka kegiatan promosi penjualan menghasilkan responsrespons yang lebih cepat dan terukur dalam penjualan daripada yang dapat dilakukan oleh iklan.

\section{Public Relation (Hubungan Pelanggan)}

bentuk promosi non personal mengenai, pelayanan atau kesatuan usaha tertentu dengan jalan mengulas informasi/berita tentangnya (pada umumnya bersifat ilmiah). Publisitas merupakan istilah yang popular bukan saja dalam dunia PR tapi dalam dunia sehari-sahari. dalam pandangan Judith Rich (dalam Lesly, 1992:257), tak ada batasan untuk ruang kreatif kegiatan publisitas itu, selain batasan-batasan etika. Namun kreatifitas yang menghasilkan karya yang bagitu kreatif dan menyenangkan namun tak memberikan apa-apa bagi apa yang dipublikasikan. Artinya, kreatifitas disini adalah kreatifitas untuk mewujudkan atau mencapai tujuan organisasi. Publisitas adalah penempatan berupa artikel, tulisan, foto, atau tayangan visual yang sarat nilai berita baik karena luar biasa, penting, atau mengandung unsur-unsur emosional, kemanusiaan, dan humor) secara gratis dan bertujuan untuk memusatkan perhatian terhadap suatu tempat, orang, orang, atau suatu institusi yang biasanya dilakukan melalui penerbitan umum. 


\section{Konsep Dasar Informasi}

Informasi adalah data yang telah diolah menjadi sebuah bentuk yang lebih berarti bagi penerimanya, dan bermanfaat dalam mengambil sebuah keputusan.

\section{Tahapan Produksi}

\section{Pra Produksi}

Pra Produksi adalah sebuah proses produksi yang merupakan tahapan awal dari seluruh kegiatan yang kan datang atau juga disebut sebagai tahapan perencanaan.

\section{Pengertian Audio Visual}

Audio Visual merupakan gabungan dari dua kata yang berarti suara dan visual yang berarti gambar, atau dengan kata lain menjelaskan audio visual adalah alat peraga yang dapat dilihat dan didengar dalam hal ini gambar bergerak menimbulkan suara.

Audio visual merupakan gabungan dari dua kata yaitu audio yang berarti suara dan bisual yang berarti gambar, atau dengan kata lain menjelaskan, "Audio Visual adalah alat peraga yang dapat dilihat dan didengar dalam hal ini gambar yang bergerak menimbulkan suara".

\section{Pengertian Broadcasting}

Broadcasting adalah distribusi audio visual atau video yang mengirimkan sinyal program untuk penonton. Para penonton mungkin masayrakat umum yang relatif besar sub-penonton, sperti anak-anak atau orang dewasa muda.

\section{Pengertian Sinopsis}

Sinopsis adalah ringkasan cerita media periklanan atau film, merupakan bentuk atau pendekatan dari sebuah periklanan atau film dengan tetap memperhatikan unsur-unsur penceriminan dari sebuah perilanan atau film tersebut.

\section{Pengertian Storyboard}

Storyboard adalah sebuah teknik shooting mangement. Disini dibuat dafta pengambilan gambar pada setiap adegan, dan divisualisasikan dalam bentuk sketsa gambar atau storyboard jika diperlukan.

\section{PROGRAM APLIKASI PENUNJANG VIDEO PROFILE} Adobe Premiere

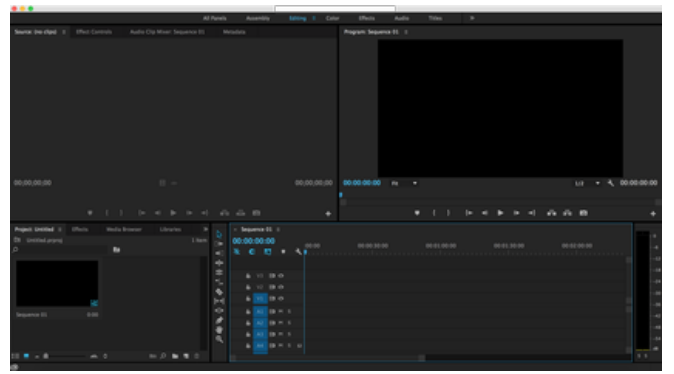

Adobe Premiere merupakan program untuk menyunting dan mendesain film dan video, disamping juga dapat digunakan untuk membuat desain iklan.

\section{LITERATURE REVIEW}

1. Media Video Company Profile Sebagai Sarana Informasi dan Promosi di PT. Surya TOTO Indonesia Tbk. Kabupaten Tangerang adalah salah satu judul Jurnal yang dibuat oleh Erna Astryani, Andri Lukmana, dan Agung Irawan selaku Dosen dan Mahasiswa STMIK 
Raharja Jurusan Teknik Informatika. Penelitian ini menjelaskan tentang pembuatan video company sebagai sarana informasi dan promosi untuk meningkatkan suatu image atau citra dari masyarakat agar tertarik dengan produk dari PT. TOTO Indonesia Tbk. Kabupaten Tangerang.

2. Design Video Profile Based Multimedia Audio Visual and Broadcasting As a Media Promotion adalah salah satu judul Jurnal yang dibuat oleh Lusyani Sunarya, Puri Apryllia, dan Siti Isnani selaku Dosen dan Mahasiswa di STMIK Raharja jurusan Teknik Informatika. Penelitian ini menjelaskan tentang pembuatan video profile sebagai media promosi Padjadjaran suites Business \& Conference Hotel kepada audience, cara merancang video profile yang menarik dan efektif dengan membuat sebuah video profile berisikan tentang keunggulan dan fasilitas yangdimiliki hotel tersebut.

3. KPM Sebagai Pedoman Multimedia Audio Visual dan Broadcasting adalah salah satu judul Jurnal yang dibuat oleh Untung Rahardja, Sugeng Widada, dan Dewi Immaniar Desrianti selaku Dosen dan Mahasiswa di STMIK Raharja. Penelitian ini menjelaskan bebagai Konsep Produksi MAVIB (KPM) menggunakakan effect CGI dalam menunjang promosi Konsentrasi MAVIB, Jurusan Teknik Informatika pada Perguruan Tinggi Raharja dapat membantu dalam merancang persiapan proses produksi sampai pra produksi.

4. Pembuatan Video Profil Sekolah Menengah Pertama Negeri 4 Polokarto Kabupaten Sukoharjo Dengan Menggunakan Komputer Multimedia adalah salah satu jurnal yang dibuat oleh Sri Maryati dan Bambang Eka Purnama dalam Journal Speed - Sentra Penelitian engineering dan Edukasi Vol. 5 No. 1 - 2013 - ijns.org. Penelitian ini menjelaskan pembuatan video profile Sekolah Menengah Pertama negeri 4 Polokarto Kabupaten Sukoharjo Dengan Menggunakan Komputer Multimedia melakukan pengambilan gambar dengan lengkap dan lebih baik, menambah kreativitas penyusunan video, tanpa meninggalkan tujuan utama pembutan video profil sebagai video dokumentasi yang memiliki ciri khusus, dan tenttu berbeda dengan video clip, atau video hiburan yang lain.

5. Pembuatan Video Profil Tiga Dimensi (3D) Sentra Ponsel Kudus adalah judul jurnal yang dibuat oleh Novan Andre Prastyo dalam Journal Speed - - Sentra Penelitian Engineering dan Edukasi Vol. 2 No. 4 - 2010 - ijns.org. Penelitian ini menjelaskan tentang pembuatan video profil tiga dimensi (3D) di Sentra Ponsel Kudus sehingga menarik masyarakat untuk datang dan membeli produk-produk yang ditawarkan.

6. Pembuatan Video Profile Tiga Dimensi (3D) Octrash Gemolong Kabupaten Sragen adalah salah satu judul jurnal yang dibuat oleh Syaiful Nurudin, Nugroho agung Prabowo selaku Mahasiswa Universitas Surakarta. Penelitian ini menjelaskan tentang pembuatan video profile tiga dimensi (3D) di Octrash Gemolong Kabupaten Sragen untuk memberikan informasi ke masyarakat bahwa OCTRASH tidak hanya sekedar penyedia layanan video shooting, tetapi juga penyedia layanan yang lainnya.

\section{METODE PENELITIAN}

Untuk memperoleh data yang lebih akurat dipenelitian ini, terdiri beberpa penerapan metode penelitina, yaitu :

(1) Metode Analisa Permasalahan. Metode ini merupakan suatu metode yang digunakan untuk menentukan topik permasalahan penelitian, dalam hal ini dilakukan dengan bentuk 
interview yang digunakan untuk memperkenalkan jurusan Teknik Informatika lebih tepatnya lagi Konsentrasi Multimedia Audio Visual and Broadcasting (MAViB) dalam prose mempromosikan jurusan tersebut.

(2) Metode Pengumpulan Data yaitu cara untuk mendapatkan data dengan jalan pengamatan secara langsung ke lokasi (Observasi), Interview ataupun kajian pustaka

(3) Analisa Data berupa pengolahan data atau informasi yang diangkat dari hasil perancangan dan penelitian terhadap Video Company Profile Sebagai Sarana Informasi Dan Promosi Jurusan Teknik Informatika Konsentrasi Multimedia Audio Visual And Broadcasting (Mavib) Perguruan Tinggi Raharja Kota Tangerang yang akan dianalisa dan diolah menggunkan software atau aplikasi program yang mendukung dalam proses perancangan

(4) Metode Analisa Perancangan, dalam produksi Perancangan Video Company Profile Sebagai Sarana Informasi Dan Promosi Jurusan Teknik Informatika Konsentrasi Multimedia Audio Visual And Broadcasting (Mavib) Perguruan Tinggi Raharja Kota Tangerang dipergunakan aplikasi-aplikasi penunjang diantaranya apliksi Adobe Premier sebagai pengolah video setelah dilakukan produksi hingga pembuatan credit title.

\section{PRE PRODUCTION}

\section{Storyboard}

\section{SCENE 1 :}

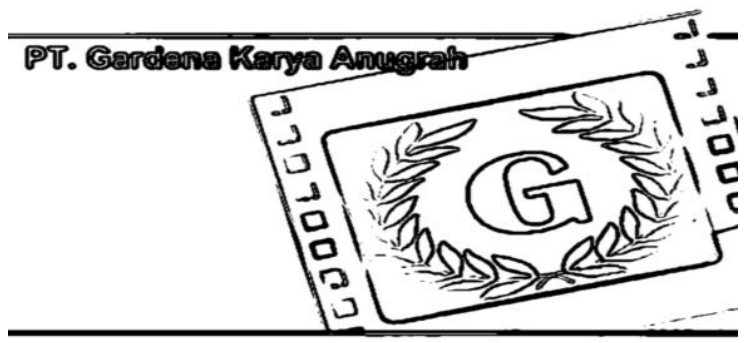

Scene 1:Bumper Opening Tulisan PT. Gardena Karya Anugrah Kota Tangerang dan logo

SCENE 2:

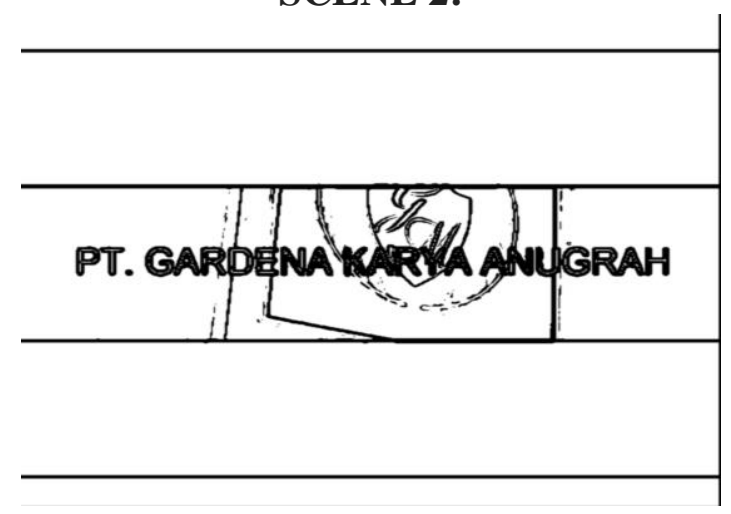

Scene 2:Slide Video 


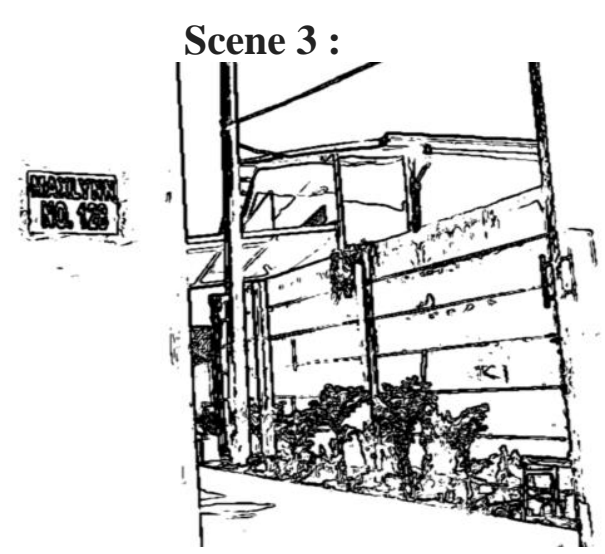

Scene 3: EXT/Pintu Gerbang PT. Gardena Karya Anugrah Kota Tangerang / FS

SCENE 4 :

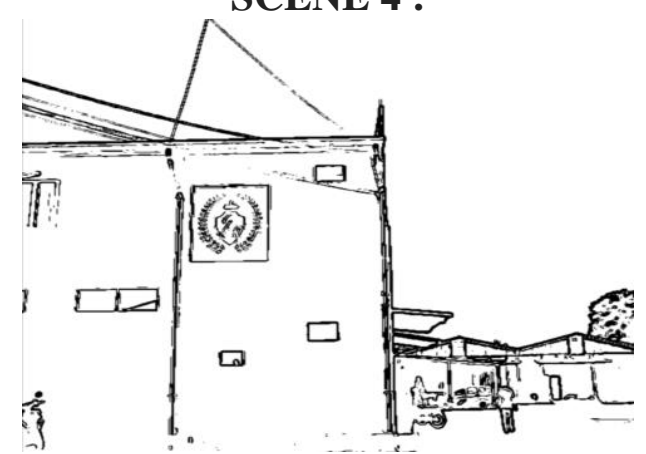

Scene 4: EXT/Gedung PT. Gardena Karya Anugrah Kota Tangerang / FS

SCENE 5 :

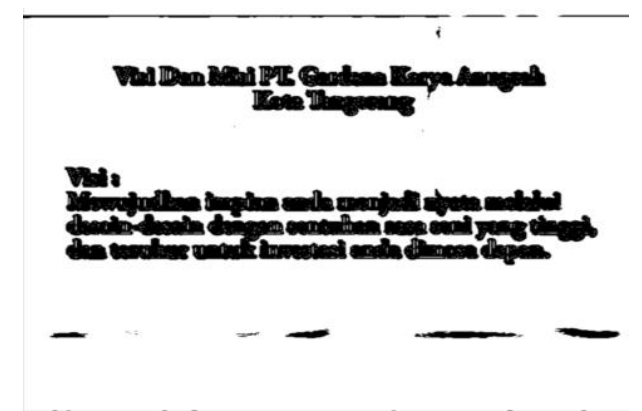

Scene 5: Visi dan Misi PT. Gardena Karya Anugrah Kota Tangerang

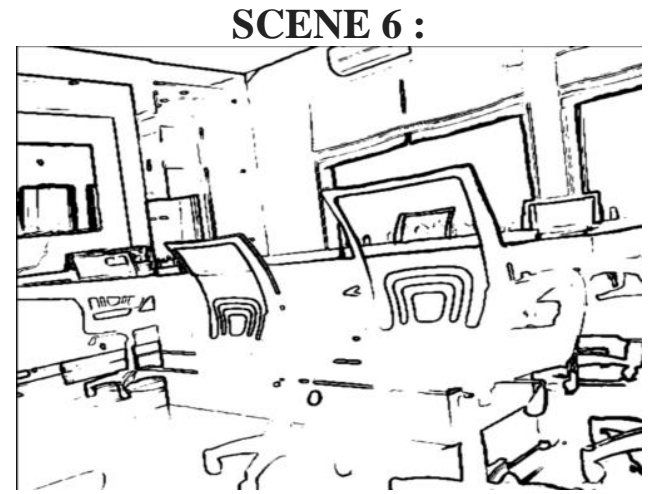

Scene 6: INT/Ruang Rapat PT. Gardena Karya Anugrah Kota Tangerang / MFS 


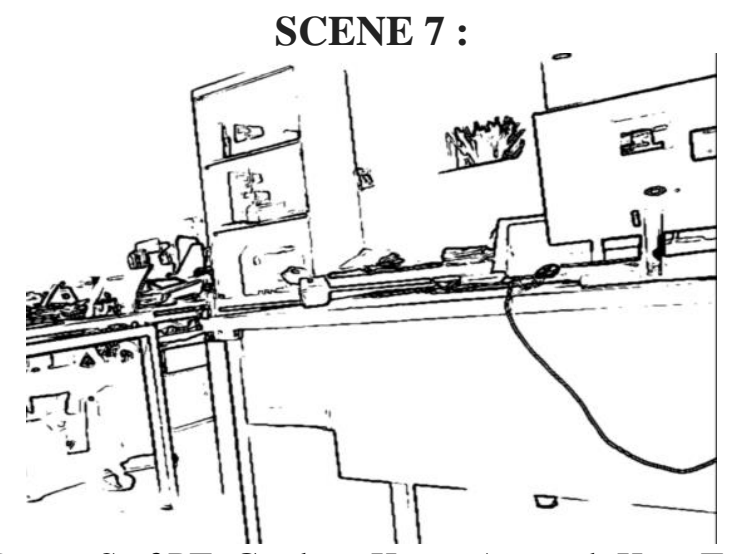

Scene 7: INT/Ruang Staf PT. Gardena Karya Anugrah Kota Tangerang / MFS

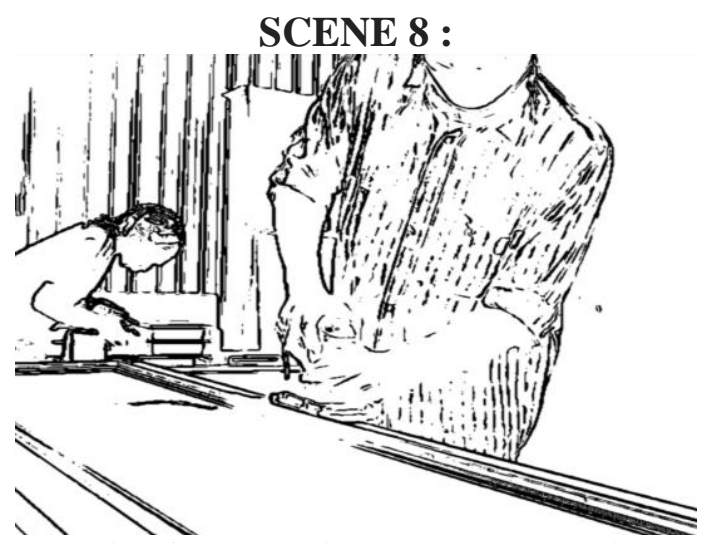

Scene 8: INT/Ruang Produksi PT. Gardena Karya Anugrah Kota Tangerang / MFS

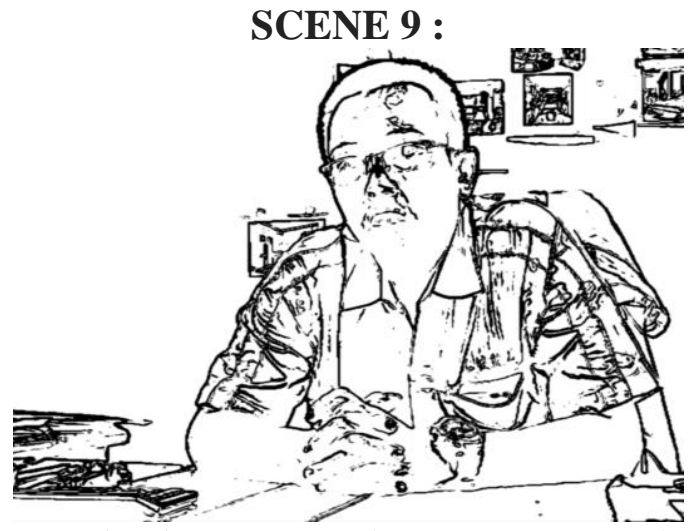

Scene 9: INT/Wawancara Pimpinan PT. Gardena Karya Anugrah Kota Tangerang / MS

\section{Alat-Alat Yang Dipakai Dalam Produksi}

Alat yang dipakai saat produksi pembuatan video company profile antara lain adalah Camera sebagai pengambilan gambar,Tripod sebagai penyangga kamera, dan Boomer sebagai peredam suara yang masuk dalam perekaman gambar. 


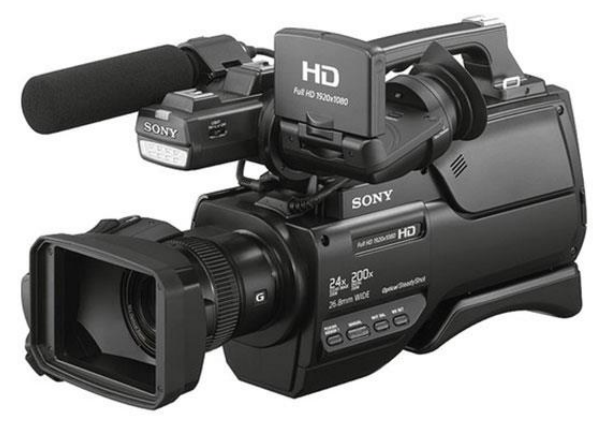

Gambar 10. Kamera Sony HD

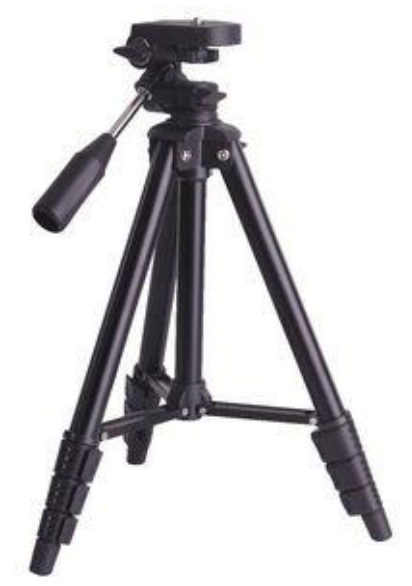

Gambar 11. Tripod

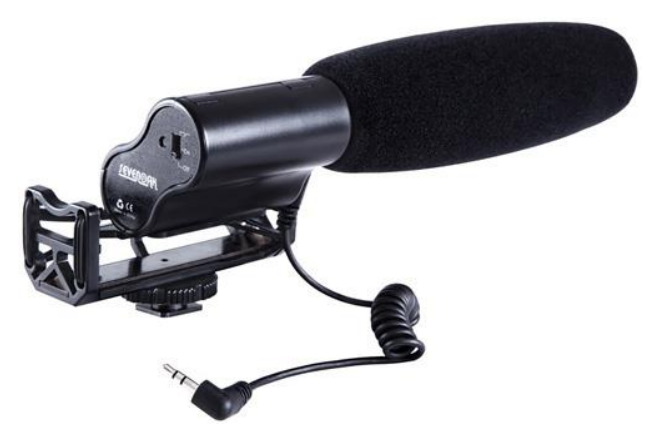

Gambar 12. Slider

\section{PRODUCTION}

Metode ataupun teknik bagaimana produksi itu dilaksanakan. Produksi adalah kegiatan untuk menciptakan danan menambah kegunaan (Utility) suatu barang dan jasa. Menurut Ahyari (2002) proses produksi adalah suatu cara, metode ataupun teknik menambah keguanaan suatu barang dan jasa dengan menggunakan faktor produksi yang ada. 


\section{POSTPRODUCTION \\ Post Production}

Menjelaskan tahapan akhir produksi yang meliputi Capturing dan Editing yang disalurkan melalui DVD dan Website.Setelah post production selesai maka video siap didistribusikan sesuai yang diinginkan.

a. Proses capture video (capturing) adalah proses memindahkan hasil shoot ke komputer dan melalui proses editing file tersebut dapat diputar dalam format Avi.

b. Editing adalah proses bagaimana mengedit video dengan penambahan title,animasi,effects,musik, audio dubbing menggunakan Adobe Premiere.

\section{KESIMPULAN}

Telah dihasilkan sebuah video company profile tentang promosi PT. Gardena Karya Anugrah Kota Tangerang yang berisi tentang video company profile, dengan model diantaranya Dewata Etnic Design yang mempunyai acuan produk pada kerajinan-kerajinan asli Indonesia seperti furniture yang berbahan dasar dari rotan dan eceng gondok dan yang mengandung unsur ukiran khas dari Jepara Jawa Tengah. Kemudian Natural Home and Décor yang mempunyai acuan produk pada model simplesity dan unsur modern yang memakai unsur besi. Selain itu terdapat produk berlabel Victory Collection, produk ini menganut gaya klasik yang menggunakan ornamen-ornamen romawi kuno.

\section{DAFTAR PUSTAKA}

[1] Arifin, Eva. 2010. “Broadcasting To Be Broadcaster”. Graha Ilmu. Yogyakarta

[2] Arriesanti, Hani Dewi, Muhammad Yusup, Ceria Marcelia. Penerapan Multimedia Audio Gallery iLearning Community And Service (Magics) Sebagai Media Penyimpanan Dokumentasi Pada Perguruan Tinggi Raharja. Journal CCIT Vol. 7 No. 2 -Januari 2014. Perguruan Tinggi Raharja. Tangerang

[3] Atmohoetomo,Soegito. 2010. "Media Audio Visual Pendidikan dan Proses Produksi Peogrammnya". Pusdiklat Perpustakaan IKIP. Yogyakarta

[4] Ayuningtyas, Melvy. 2011. "Ngedit Video Dengan Adobe Premiere CS3". Dunia Komputer. Yogyakarta

[5] Binanto, Iwan. 2010. Multimedia Digital (Dasar Teori dan Pengembangannya). ANDI. Yogyakarta

[6] Halim, Cipta. 2010. "Tips Praktis Promosi Online Untuk Berbagai Event”. Gramedia. Jakarta

[7] Hendratman Hendi, ST. 2010. "The Magic of Adobe After Effects". Informatika. Bandung

[8] Immaniar, Dewi, Sudaryono dan Dwi Ayu Ningrum. 2012. "Enriching Company Profile Sebagai Penunjang Media Informasi Dan Promosi Pada Perguruan Tinggi Raharja", Jurnal CCIT Vol. 7 No. 3. Tangerang

[9] Immaniar, Dewi, Untung Rahardja, Reni Mulyani. 2012. Audio Visual As One Of The Teaching Resources On iLearning. Journal CCIT Vol. 5 No. 2. Tangerang

[10] Kuswandi, Wawan. 2010. Komunikasi Massa Sebuah Analisis Media Televisi. Rineka Cipta. Jakarta

[11] Kotler dan Amstrong. 2010. Principles of Marketing (Edisi 13). Pearson. United of America

[12] Lukiati, Komala. 2010. Paduan Mudah Merancang Bangunan. Niaga Swadaya. Jakarta 
[13] Novtrian, Riki, Ratih Oktaviani, Fiktori Agus Saputro. 2010. Multimedia Sebagai Pembuatan Company Profile Pada Sekolah Menengah Seni Rupa Yogyakarta. STMIK AMIKOM YOGYAKARTA. Yogyakarta

[14] Maimunah, Lusyani Sunarya, Nina Larasati. 2012. Media Company Profile Sebagai Penunjang Informasi dan Promosi. Journal CCIT Vol 5 No. 3. Tangerang

[15] Maryati, Sri. Bambang Eka Purnama. Pembuatan Video Profil Sekolah Menengah Pertama Negeri 4 Polokarto Kabupaten Sukoharjo Dengan Menggunakan Komputer Multimedia. Journal Speed - Sentra Penelitian Engineering dan Edukasi Vol. 5 No. 1 2013 - ijns.org

[16] Prastyo, Novan Andre. Pembuatan Video Profil Tiga Dimensi (3D) Sentra Ponsel Kudus. Journal Speed - Sentra Penelitian Engineering dan Edukasi Vol. 2 No. 4 - 2010 - ijns.org

[17] Rahardja, Untung, Sugeng Widada, Dewi Immaniar Destrianti. 2010. KPM Sebagai Pedoman Produksi Media MAVIB (Multimedia Audio Visual and Broadcasting). Journal CCIT Vol. 3 No. 2 